Journal of

Molecular Microbiology

and Biotechnology

\title{
Identification of Two DNA Helicases UvrD and DinG as Suppressors for Lethality Caused by Mutant cspA mRNAs
}

\author{
Jihwan Hwang a, b Kangseok Lee $^{\mathrm{b}}$ Sangita Phadtare ${ }^{\mathrm{a}}$ Masayori Inouye ${ }^{\mathrm{a}}$ \\ ${ }^{a}$ Department of Biochemistry, Center for Advanced Biotechnology and Medicine, Robert Wood Johnson Medical \\ School, University of Medicine and Dentistry of New Jersey, Piscataway, N.J., USA; b Department of Life Science, \\ Chung-Ang University, Seoul, South Korea
}

\section{Key Words \\ CspA protein $\cdot$ Cold shock $\cdot$ DNA helicase $\cdot$ UvrD DNA \\ helicase $\cdot$ DinG DNA helicase}

\begin{abstract}
CspA is a major cold shock-inducible protein (70 aa), and its major role in the cold shock response was shown to be as an RNA chaperone destabilizing secondary structure of mRNAs at low temperature. Previously, we showed that the overexpression of mutant $\operatorname{csp} A$ containing premature non-sense codons at various positions led to stalled ribosomes on mutant $\operatorname{csp} A$ transcripts, ultimately leading to cell death. This lethality is primarily due to the highly translatable $\operatorname{csp} A 5^{\prime}$ UTR that recruits most of the ribosomes from other mRNAs, which are then stalled at the abnormal stop codon. This was called the 'LACE' effect. We show here that non-sense mutation even at the 67th position as well as substitutions of aromatic amino acid residues present on the RNA-binding surface of CspA protein to alanine caused the LACE effect by trapping a substantial amount of ribosomes on $\operatorname{csp} A$ mRNAs. In an attempt to identify a suppressor(s), which may help the cells to recover from the inhibitory LACE effect, genetic screening of an Escherichia coli genomic library was performed. We isolated suppressors that contained the genom-
\end{abstract}

ic fragments encoding uvrD and $\operatorname{din} G$, respectively, whose gene products are ATP-dependent DNA helicases. The nucleic acid-binding and ATPase activities of these two helicases were found to be essential for their suppression activity. This genomic screening offers an approach to shed light on the mechanistic of $5^{\prime}-U T R$ of $\operatorname{cspA}$ mRNA and novel roles of $E$. coli helicases that function in DNA repair.

Copyright $\odot 2012$ S. Karger AG, Base

\section{Introduction}

Low temperature is one of the major environmental stresses encountered by bacteria. The genome-wide analysis of Escherichia coli revealed that there are more than twenty-six cold shock-inducible genes [Gualerzi et al., 2003; Phadtare and Inouye, 2004], and among them CspA is a major cold shock-inducible protein. CspA was shown to function as an RNA chaperone which destabilizes unfavorable secondary structures of RNAs [Goldstein et al., 1990; Jiang et al., 1997]. E. coli contains nine CspA homologues-CspA to CspI, which can substitute for each other during cold shock response [Xia et al., 2001b]. Out of these, CspA, CspB, CspG and CspI are cold shock inducible. Deletion of single $\operatorname{csp} A$ homologue does not lead to

\section{KARGER}

Fax +4161306 1234

E-Mail karger@karger.ch

www.karger.com
(C) 2012 S. Karger AG, Basel

$1464-1801 / 12 / 0223-0135 \$ 38.00 / 0$

Accessible online at:

www.karger.com $/ \mathrm{mmb}$
Sangita Phadtare

Department of Biochemistry, Center for Advanced Biotechnology and Medicine Robert Wood Johnson Medical School, University of Medicine and Dentistry of New Jersey, 679 Hoes Lane, Piscataway, NJ 08854 (USA)

Tel. +1 732235 3912, E-Mail phadtasa@ umdnj.edu 
cold sensitivity; however, a quadruple deletion mutant, $\triangle c s p A B G E$, is cold sensitive [Xia et al., 2001b].

The expression of $\operatorname{csp} A$ at low temperature is transiently and drastically stimulated, and reaches its basal level during an adaptive acclimation period after cold shock [Phadtare, 2004; Xia et al., 2002]. The robust production of $\operatorname{csp} A$ at low temperature is based on both transcriptional and posttranscriptional regulation of the cspA gene [Gualerzi et al., 2003]. Initially, it was believed that the promoter sequences possessing AT-rich UP element [Mitta et al., 1997] promptly respond to a temperature downshift to achieve robust transcription upon cold shock [Fang et al., 1999]; however, later on it was shown that transcription does not play a major role in the lowtemperature expression of $\operatorname{csp} A$ [Phadtare and Severinov, 2005], and that $\operatorname{csp} A$ can be transcribed efficiently even at $37^{\circ} \mathrm{C}$ [Brandi and Pon, 2012]. On the other hand, mRNA stabilization plays a crucial role in the cold shock expression of $\operatorname{csp} A$. The stability of $\operatorname{csp} A$ mRNA increases $\sim 70$ - to 100 -fold at $15^{\circ} \mathrm{C}$ compared to that at $37^{\circ} \mathrm{C}$ [Fang et al., 1997; Goldenberg et al., 1996; Gualerzi et al., 2003; Xia et al., 2002]. In addition, this stabilized transcript undergoes the overall secondary structural rearrangements within the open reading frame (ORF) of transcript rather than within a long $5^{\prime}-U T R$ (untranslated region), and the conformer at $15^{\circ} \mathrm{C}$ is more preferentially accessed by $30 \mathrm{~S}$ subunit and fMet-tRNA leading to efficient CspA production than that at $37^{\circ} \mathrm{C}$ [Giuliodori et al., 2010]. Furthermore, translational apparatuses such as IF3 and ribosome extracted from cold-shocked cells were shown to selectively translate $\operatorname{csp} A$ transcripts [Giuliodori et al., 2004], suggesting a pivotal role of translation control in CspA production at low temperature.

This specific and selective translation of $\operatorname{csp} A \mathrm{mRNA}$ at low temperature was previously suggested to occur by LACE (the low temperature-dependent antibiotic effect of truncated $\underline{c} p A$ expression) phenotype [Jiang et al., 1996a, b; Xia et al., 2001c]. Overexpression of mutant $\operatorname{csp} A$ encoding a premature non-sense codon at position 2,11 or 31 caused the growth inhibition with stalled monosome, disomes or trisomes, respectively, on mutant $\operatorname{csp} A$ transcripts, ultimately leading to cell death. This lethality is primarily due to the highly translatable $5^{\prime}$-UTR that recruits most of ribosomes being stalled at the abnormal stop codon [Xia et al., 2001c]. Within the $5^{\prime}-U T R$ of $\operatorname{csp} A$ mRNA, there are two cis-elements for the efficient expression of CspA at low temperature. One is the 26-baselong 'upstream box' which spans from -42 to $-17(+1, \mathrm{~A}$ of initiation codon AUG). This sequence was complementary to the sequences from bases $1,021-1,035$ of the
$16 \mathrm{~S}$ ribosomal RNA [Xia et al., 2001c; Yamanaka et al., 1999]. The second is Shine-Dalgarno sequence including an initiation codon. The alterations in these cis-elements abolished the lethal effect by a premature non-sense codon [Xia et al., 2001c]. The harmful LACE effect resulted in the derepression of $\operatorname{csp} A$ transcripts at low temperature [Xia et al., 2001c] and was suppressed by an exogenously expressed CspA, suggesting its role in negative regulation [Jiang et al., 1996b]. The complete deletion of cspA ORF caused the derepression of $5^{\prime}-U T R$, and simultaneously the repression of $5^{\prime}-U T R$ expression in $\triangle c s p A$ slowly progressed, suggesting that there may exist a negative transfactor besides CspA [Bae et al., 1997]. Whether directly or indirectly CspA regulates its own synthesis is elusive at present; nevertheless, LACE may help to comprehend the roles of 5'-UTR of cspA mRNA in its efficient translatability and of CspA in its negative autoregulation of mRNA.

In this study, in order to elucidate the regulation of CspA by its own transcripts, we further explored the growth inhibition caused by a series of C-terminal truncation and full-length mutant CspA proteins. Moreover, as an approach to identify a trans-factor(s) that substitute the function of CspA, we constructed a genomic library from the quadruple cspABGE-deletion strain [Xia et al., 2001a], and screened the library clones that suppress the growth inhibition. Peculiarly, two suppressor clones were identified to be ATP-dependent DNA helicases, UvrD and DinG. More interestingly, the LACE phenotype was not functionally suppressed by another DNA helicase Rep whose function overlaps with UvrD and DinG. Our results provide an insight into the regulation of CspA by its mRNA and can be further explored to understand the role of DNA helicases in suppression of the LACE effect.

\section{Results}

\section{LACE, the Absence of Full-Length CspA}

As described above, the highly expressed mutant $\operatorname{csp} A$ mRNAs bearing a premature non-sense codon at position 2, 11 or 31 stalled monosome, disomes or trisomes, respectively, on mutant $\operatorname{csp} A$ transcripts. This eventually led to cell death [Xia et al., 2001c]. The pattern of ribosomes stalled on cspA transcripts was strictly dependent on the length of coding sequences of mutant $c s p A$ mRNA. In order to further investigate the LACE phenotype, we incorporated TAA stop codon at every third residue between 52nd and 67th positions in CspA. The strain BX02 $(\Delta c s p A G)$ was used for this experiment [Xia et al., 2001c], 
as (a) due to the lack of $\operatorname{csp} A$ coding sequence in this strain, it is possible to distinguish plasmid-derived $\operatorname{csp} A$ mRNAs from chromosomal transcripts, and (b) unlike the BX04 strain $(\triangle \operatorname{csp} A B G E)$, temperature-sensitive phenotype was not observed at low temperature with the BX02 $(\Delta c s p A G)$ strain. BX02 cells were transformed with plasmids as shown in figure 1a, and colony formation was tested on LB plate at either $37^{\circ} \mathrm{C}$ or $15^{\circ} \mathrm{C}$. All of these plasmids enabled $\mathrm{BX} 02$ cells to form colonies at $37^{\circ} \mathrm{C}$; however, at $15^{\circ} \mathrm{C}$, only the cells harboring pUC19 or pJJG02 plasmids were able to form colonies. None of the cells carrying the mutant plasmids were able to grow at low temperature (fig. 1b). This growth inhibition was quantitatively measured in liquid media. The overnight cultures grown at $37^{\circ} \mathrm{C}$ were diluted in a fresh LB medi$\mathrm{um}$, and the diluted cultures were first incubated at $37^{\circ} \mathrm{C}$. After 2-hour incubation, the cultures were transferred to $15^{\circ} \mathrm{C}$, and the results (fig. 1c) were consistent with those seen in figure $1 \mathrm{~b}$. Because the cells carrying a stop codon in the $\operatorname{csp} A$ coding region at 31 st position showed dramatic accumulation of trisomes [Xia et al., 2001c], we examined polysome profiles of cells containing pA51S and pA66S. These two plasmids were chosen because of the length of coding sequences between the two non-sense codons, which is long enough for at least one ribosome to occupy. BX02 cells harboring pA51S or pA66S were grown at $15^{\circ} \mathrm{C}$ for $1 \mathrm{~h}$, and polysome samples were prepared as carried out previously [Xia et al., 2001c]. Cells harboring pJJG02 showed numerous small peaks at polysome positions; however, more tetrasomes and pentasomes were accumulated in cells transformed with pA51S and pA66S, respectively, compared to the cells harboring pA30S (fig. 1d), suggesting that translating ribosomes were stalled at each premature stop codon. This indicates that truncation of the C-terminal residues affected the function of CspA, and implies that full-length CspA is engaged in its own translational control through an RNA chaperone activity as none of C-terminus truncated CspA mutants in figure la is able to complement the cold sensitivity of strain BX04 $(\Delta c s p A B G E)$ (online suppl. fig. S1; see www.karger.com/doi/10.1159/000339832 for all online suppl. material).

\section{LACE Induced by Aromatic Amino Acid Substitutions of CspA}

The three-dimensional structure of E. coli CspA revealed that it contains unusually exposed aromatic amino acid patch composed of Trp ${ }^{11}, \mathrm{Phe}^{18}, \mathrm{Phe}^{20}, \mathrm{Phe}^{31}, \mathrm{His}^{33}$ and Phe ${ }^{34}$ [Feng et al., 1998; Schindelin et al., 1994]. The residues $\mathrm{Phe}^{18}$ and $\mathrm{Phe}^{20}$ were critical for maintaining a conformational stability and binding to single-stranded nucleic acids, respectively [Hillier et al., 1998]. The residues $\mathrm{Phe}^{30}$ and $\mathrm{His}^{32}$ of E. coli CspE (the corresponding residues $\mathrm{Phe}^{31}$ and $\mathrm{His}^{33}$ in $\mathrm{CspA}$ ) were implicated in nucleic acid melting activity [Phadtare et al., 2002a, b; Phadtare et al., 2004].

The mutant plasmids described above expressed Cterminally truncated CspA proteins, which caused a LACE effect. Thus, we further examined how a fulllength CspA protein with a point mutation(s) affects the cellular growth when expressed in BX02 cells. Three plasmids pJJG02a, pJJG02b and pJJG02c were constructed as described in 'Experimental Procedures'. The respective plasmids contain single (W11A), double (F18A and F20A) or triple (F31A, H33A and F34A) mutations producing CspAa, CspAb and CspAc, respectively (fig. 2a). These plasmids were introduced in BX02 cells, and growth phenotypes were examined by incubating transformants at $37^{\circ} \mathrm{C}$ or $15^{\circ} \mathrm{C}$. At $37^{\circ} \mathrm{C}$, the expression of mutant CspA did not affect cell growth; however, at $15^{\circ} \mathrm{C}$ all of fulllength mutant CspA proteins tested caused growth inhibition (fig. 2a). The monitoring of cell growth in a liquid medium also revealed that expression of CspAa, CspAb or CspAc was detrimental to growth of BX02 cells at low temperature (fig. 2b). Next, polysome patterns were analyzed by sucrose density gradient. Interestingly, polysome profiles of cells harboring pJJG02b and pJJG02c showed high peaks of di- and trisomes with significant accumulations of tetra- and pentasomes. Note that the peak of trisomes from pJJG02c was as high as that of disomes, suggesting that CspAc caused the most severe polysome stalling. Notably, even though the discernible role of peripheral $\operatorname{Trp}^{11}$ in CspA activity is unknown, the cell growth was inhibited by the mutation of $\operatorname{Trp}^{11}$ to alanine (fig. 2a, b) accumulating relatively more polysomes than cells expressing wild-type CspA protein (fig. 2c). Nevertheless, the cold sensitivity of BX04 cells was complemented by the overexpression of CspAa using an IPTGinducible pIN plasmid (online suppl. fig. S2), implying that overexpression of $5^{\prime}$-UTR from pJJG02a is likely to be a cis-element that causes the LACE effect seen in figure 2 .

\section{Identification of Genes That Suppress the Lethality of LACE Cells}

The cells harboring CspAa plasmid showed moderate accumulation of polysomes, which was sufficient to cause LACE, implying that LACE effect is not due to the hampered translation termination, or raising a possibility that there may exist another factor which is associated with 

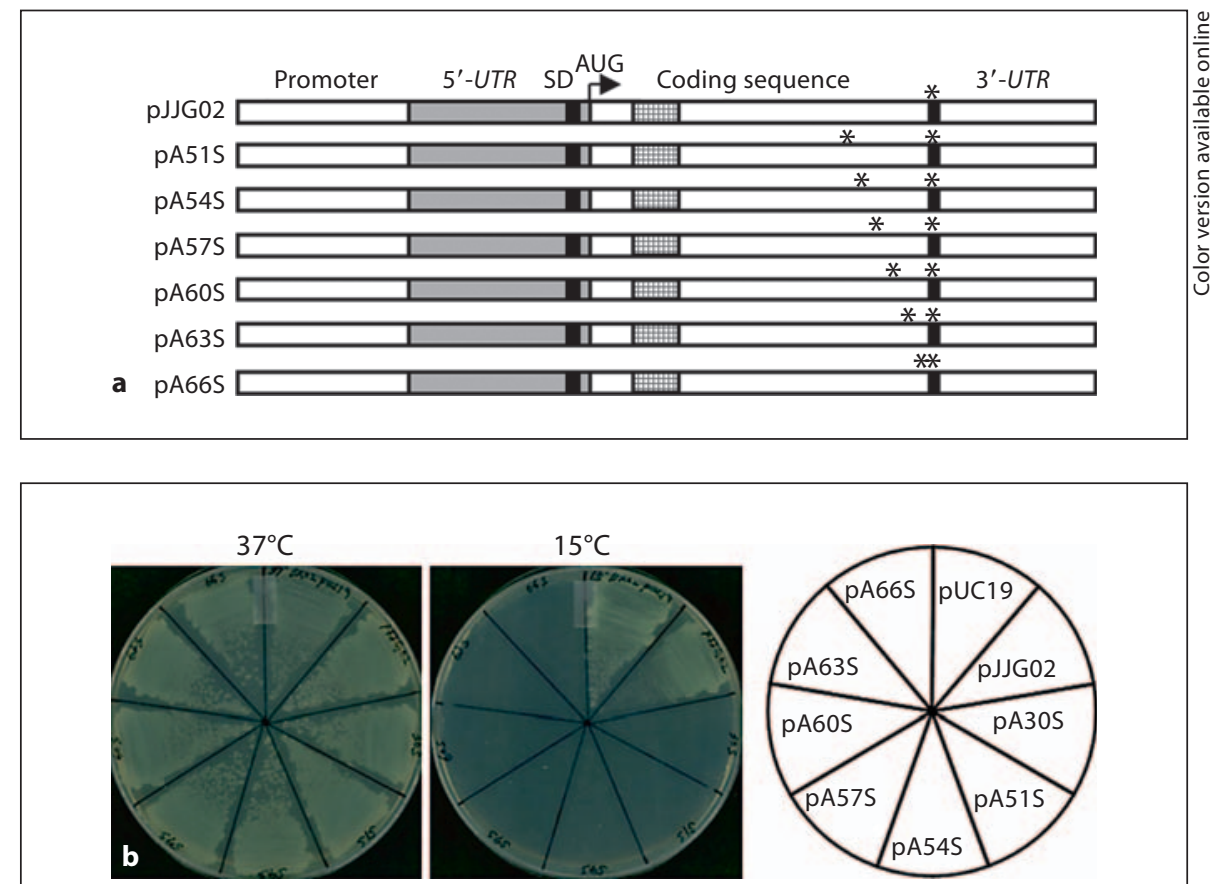

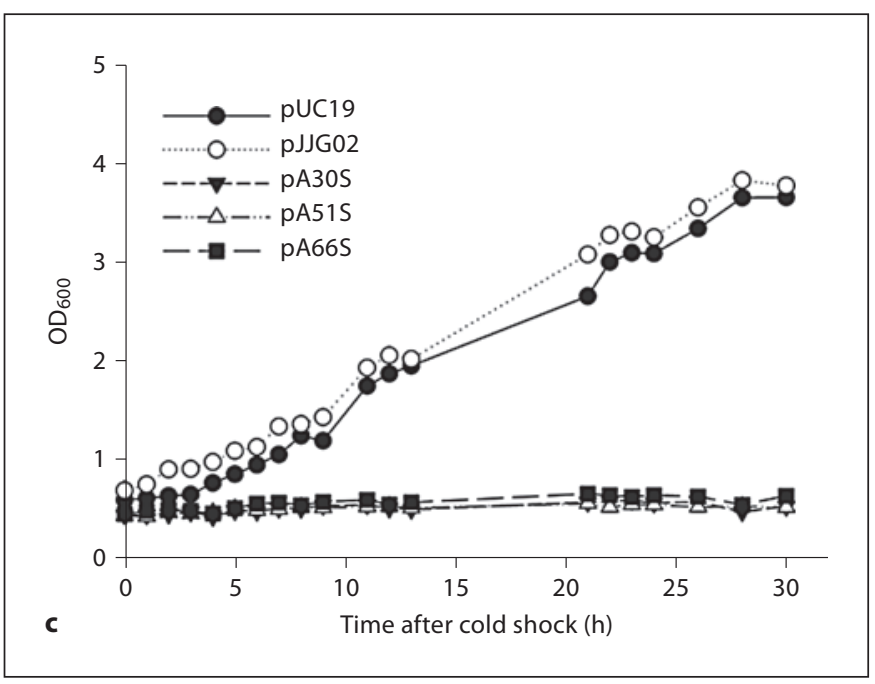

Fig. 1. Growth inhibition caused by premature stop codons in $\operatorname{csp} A$ mRNA. a Construction of the $\operatorname{csp} A$ mutants. Plasmid pJJG02 contains a wild-type cspA gene including 159-base $5^{\prime}$ - UTR, ShineDalgarno (SD) sequence and its native transcription termination sequence. The 159-base 5'-UTR is shaded, and the thick black bar in the $5^{\prime}$-UTR indicates the SD sequence. The striped box indicates the 'downstream box' region [Goldstein et al., 1990]. pA30S encodes TAA codon at the 31st amino acid residue of the $\operatorname{csp} A$ gene [Xia et al., 2001c]. pA51S, pA54S, pA57S, pA60S, pA63S and pA66S were obtained by mutating the 52nd, 55th, 58th, 61st, 64 th and 67 th codons of the $\operatorname{csp} A$ gene to TAA codon by site-directed mutagenesis using pJJG02 as a template. The black bars marked

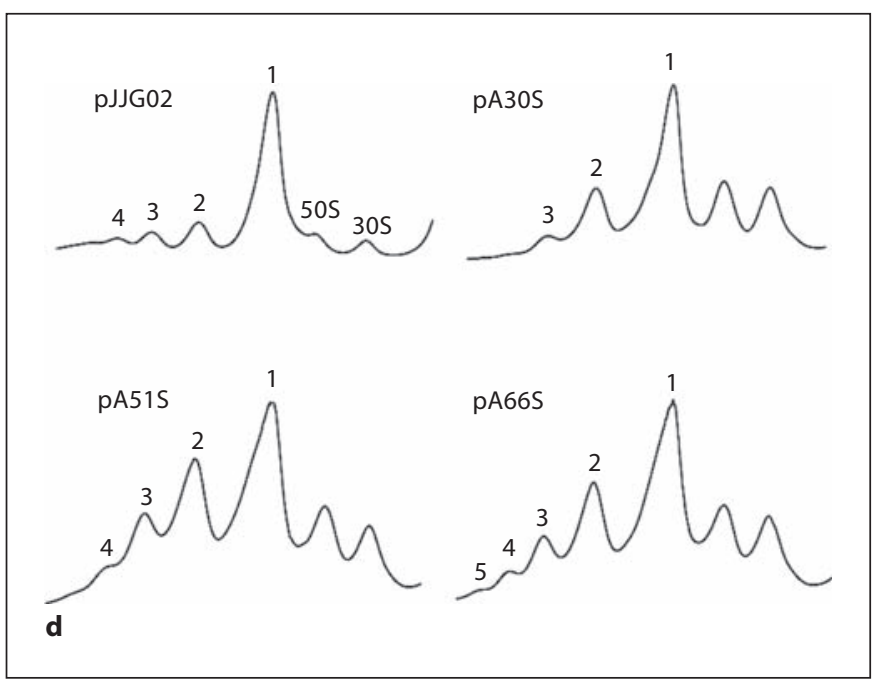

by asterisks show the positions of the TAA codon. $\mathbf{b}$ Colony formations of BX02 cells containing the $\operatorname{cspA}$ mutants at $37^{\circ} \mathrm{C}$ and $15^{\circ} \mathrm{C}$. c Growth curves of cold-shocked cells harboring different plasmids. Data from pA54s to pA63S were not shown for a clear comparison. Cell cultures were diluted five times before $A_{600}$ measurement. d Polysome profiles of BX02 cells harboring the $\operatorname{csp} A$ mutant plasmid at $15^{\circ} \mathrm{C}$. Cells were grown at $37^{\circ} \mathrm{C}$ to an exponential phase and subjected to cold shock for $1 \mathrm{~h}$, and then their polysomes were isolated and analyzed as described in 'Experimental Procedures'. 70S ribosome and polysomes are marked by the number of $70 S$ units they contain. 


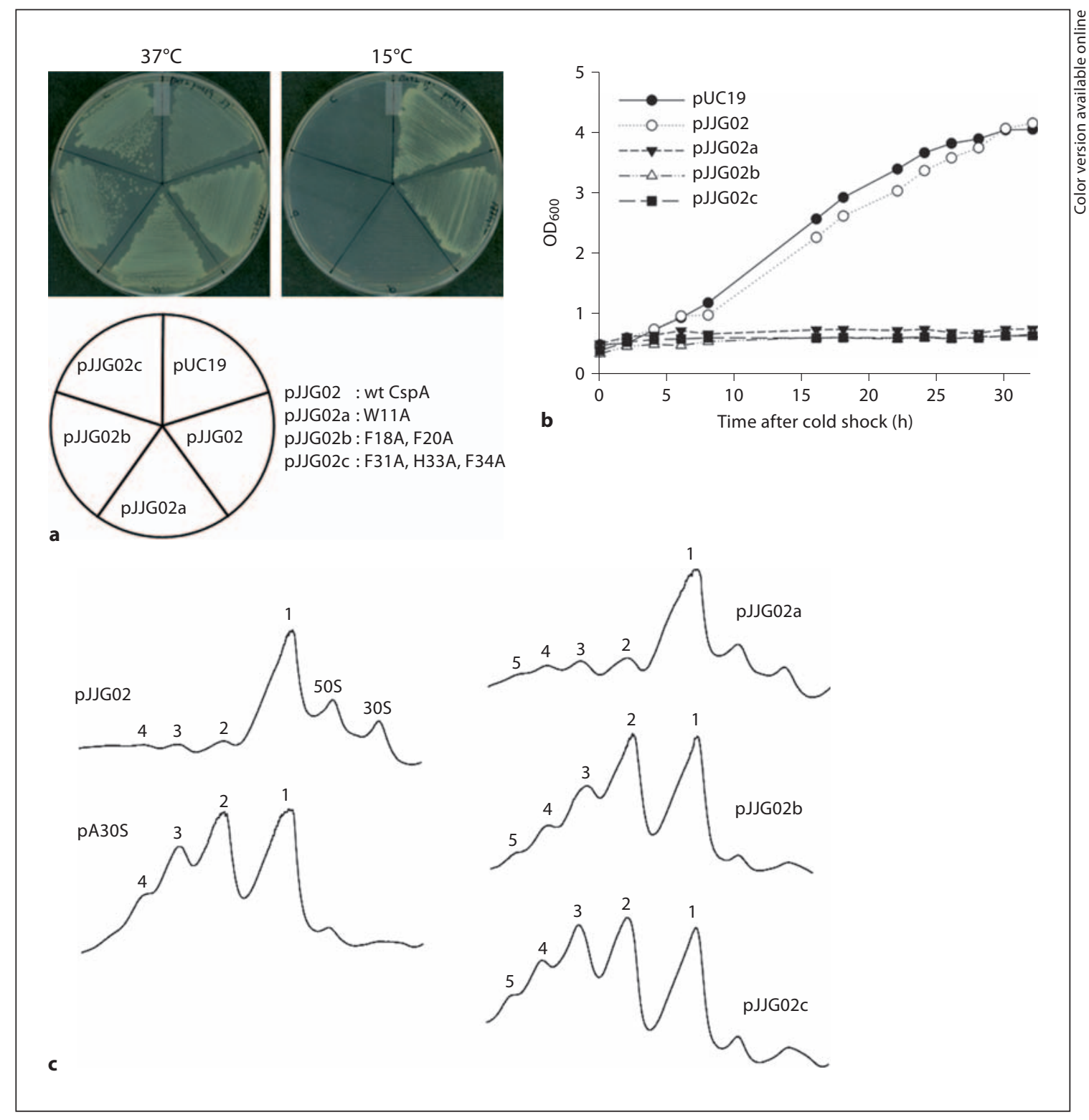

Fig. 2. Growth inhibition caused by full-length mutant CspA. a Colony formations of BX02 cells expressing full-length mutant CspA proteins at $37^{\circ} \mathrm{C}$ and $15^{\circ} \mathrm{C}$ as indicated in the figure. $\mathbf{b}$ Growth curves of cold-shocked cells harboring different plasmids. The measurement of growth was carried out as in figure 1c. c Polysome profiles of BX02 cells harboring the control or $\operatorname{csp} A$ mutant plasmids at $15^{\circ} \mathrm{C}$. Sample preparations and polysome analyses were performed as shown in figure 1d. pJJG02 and pA30S were used as a control. 70S ribosome and polysomes are marked by the number of $70 S$ units they contain.

CspA that is involved in this phenomenon. In an attempt to further understand the LACE phenotype, we constructed genomic library to search for an element(s) in the E. coli genome, which can restore the growth of LACE cells at low temperature. For this study, JM83 cells (wild type) instead of BX02 were used for the following reasons: (a) antibiotics conflicts (BX02 has $\mathrm{Cm}^{\mathrm{R}}$ and $\mathrm{Km}^{\mathrm{R}}$, pA30S has $\mathrm{Ap}^{\mathrm{R}}$ and $\mathrm{pACYC184}$ has $\mathrm{Cm}^{\mathrm{R}}$ and $\mathrm{Tc}^{\mathrm{R}}$ ) and (b) it has been observed that the overexpression of $5^{\prime}-U T R$ of $\operatorname{csp} A$ in CL83 strain, a parental strain of JM83 $\left(\operatorname{csp} A^{+}\right)$, caused the LACE effect with a derepression of genomic $\operatorname{csp} A$ expression [Jiang et al., 1996a, b], suggesting that the LACE 

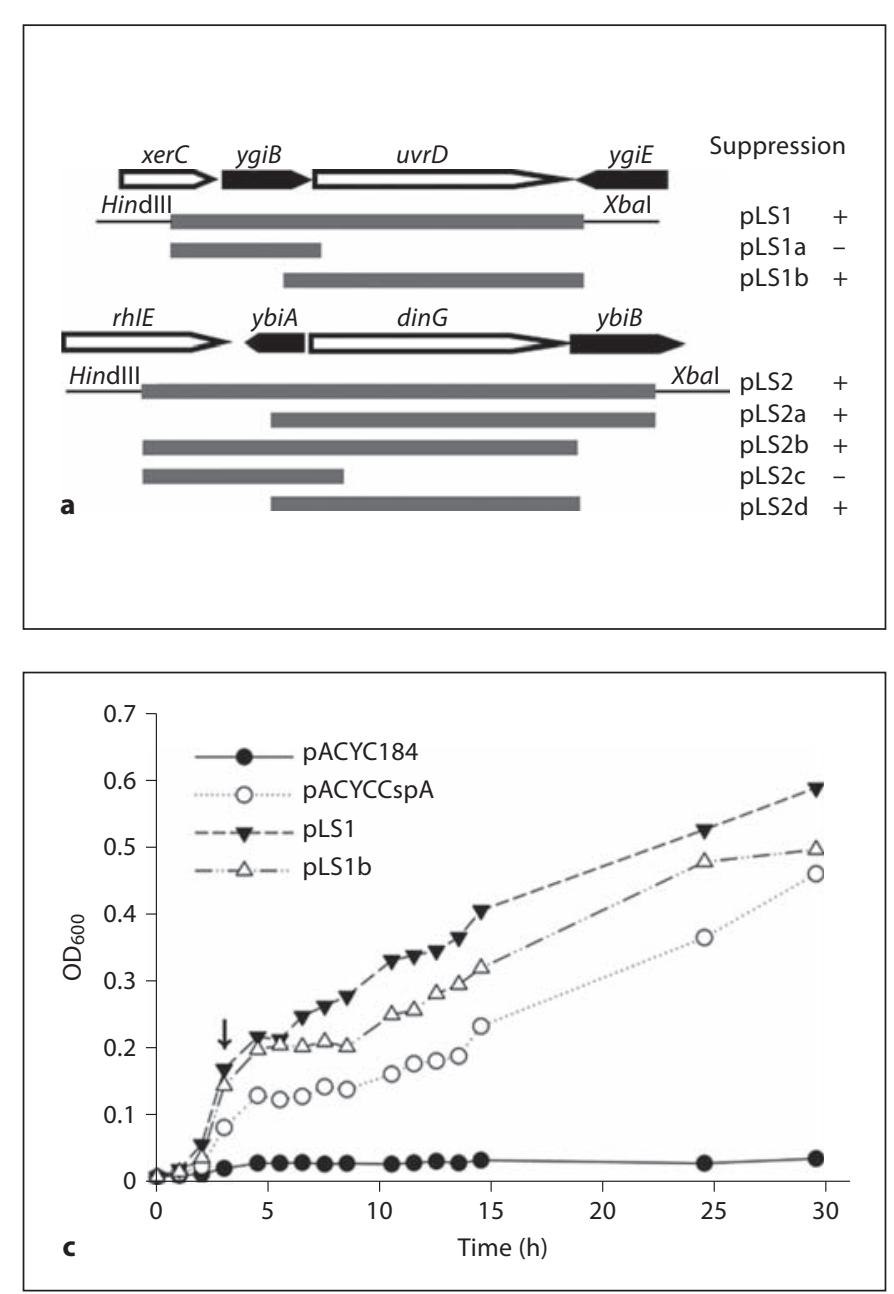

Fig. 3. Identification of the gene responsible for the suppression of the growth defect of LACE cells. a Derivatives of pLS1 and pLS2 were constructed as described in 'Experimental Procedures'. Grey bars represent original library and truncated clones. The restriction enzyme sites show the direction of clone. b JM83 cells harboring pA30S were transformed with the plasmids as indicated in a, and each transformant was re-streaked on LB plates containing

has a dominant-negative effect on genomic cspA expression. Thus, JM83 cells were transformed with pA30S (a transformant designated as JA30 strain), and the resulting transformants failed to adapt to cold shock (online suppl. fig. S3). These JA30 cells were then transformed with an E. coli genomic library constructed in pACYC184 vector. The library contained partially digested chromosomal DNA fragments from a cold-sensitive E. coli BX04 $(\triangle c s p A B G E)$. BX04 cells were used to exclude four CspA homologues which may act as suppressors of the growth inhibition seen. Transformants were tested for their ability to grow at $15^{\circ} \mathrm{C}$ on $\mathrm{LB}$ plates containing Ap and $\mathrm{Cm}$.
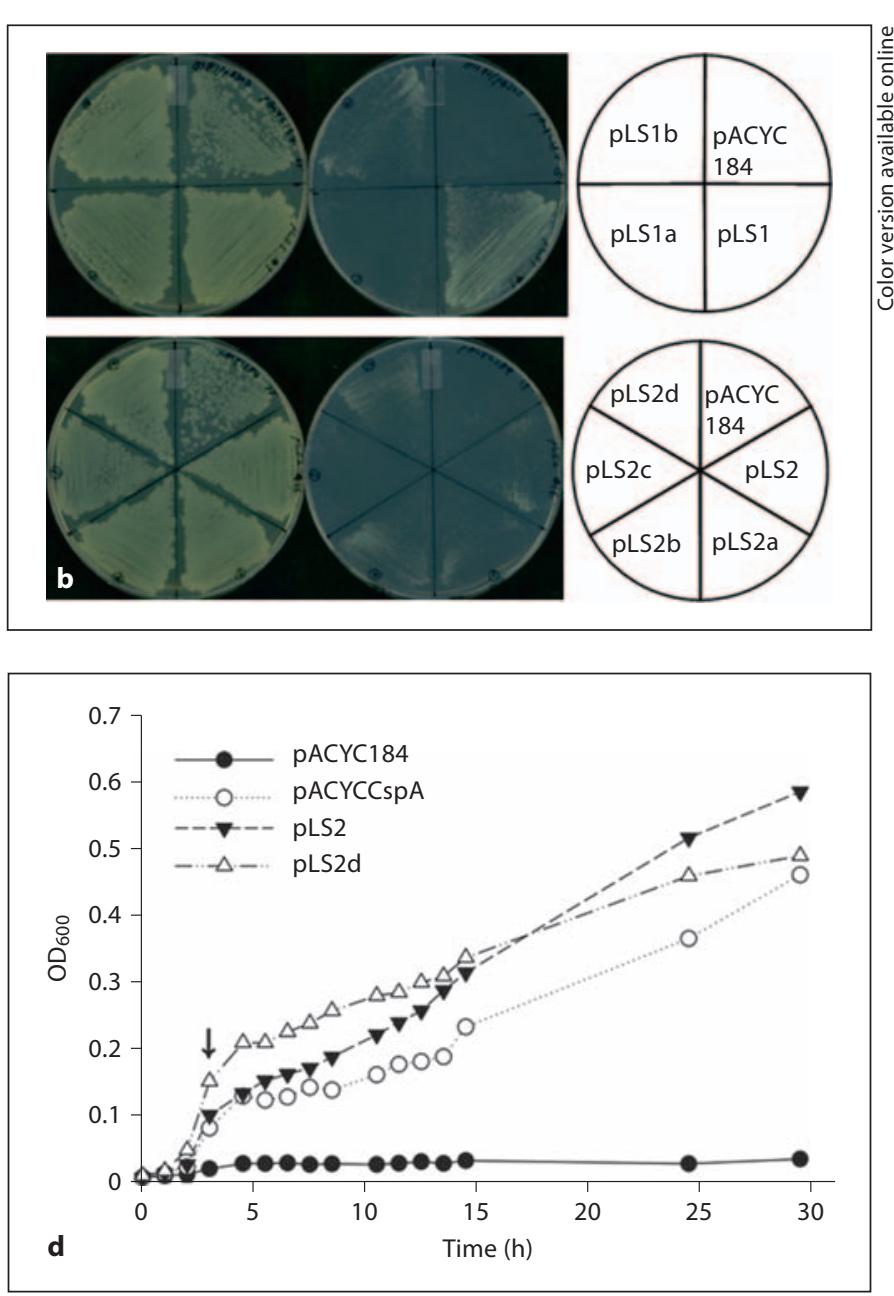

Ap and $\mathrm{Cm}$. The plates were incubated at $37^{\circ} \mathrm{C}$ or $15^{\circ} \mathrm{C} .+=$ Suppression; - = no suppression. c, $\mathbf{d}$ Growth curves of suppressor cells. JA30 cells harboring pACYC184, pACYCCspA or suppressor clones were pre-cultured in $\mathrm{LB}+\mathrm{Ap}+\mathrm{Cm}$ at $37^{\circ} \mathrm{C}$ for $3 \mathrm{~h}$; then, the cultures were subsequently incubated at $15^{\circ} \mathrm{C}$. Arrow indicates the time point of temperature downshift to $15^{\circ} \mathrm{C}$.

Plasmids from those colonies that gained the ability to grow at $15^{\circ} \mathrm{C}$ were purified and retransformed into JA30 cells to confirm their suppression activity. Approximately 200,000 transformants were screened, and eleven library clones were isolated as possible candidates for the suppressor clones. Out of 11 clones, five (pLS1) encode the uvrD gene. Among the remaining six clones, two (pLS2) contained the genomic fragment of $\operatorname{din} G$ (fig. 3a). Interestingly, the remaining four clones contained either the $y j j B$ or $y d a C$ genes. They were not further assessed in this study. 


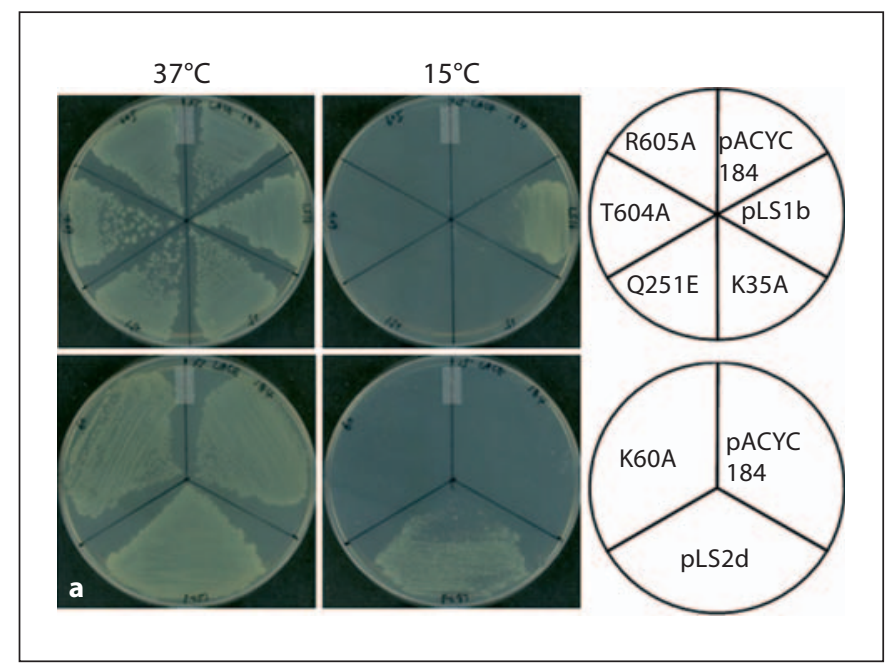

Fig. 4. Mutational analysis of UvrD and DinG for suppression effects. a The LACE cell was transformed with wild-type or mutant suppressor clones as indicated. Transformed cells were plated on LB plates containing Ap and $\mathrm{Cm}$, and the plates were incubated at $37^{\circ} \mathrm{C}$ and $15^{\circ} \mathrm{C}$. b, c Growth curves of transformants shown in a. The strains were grown at $37^{\circ} \mathrm{C}$ for $3 \mathrm{~h}$ in LB media containing Ap and $\mathrm{Cm}$, and the cultures were transferred to $15^{\circ} \mathrm{C}$ followed by further incubation. Measurements were carried out as in figure 3.

The inserted genomic element of pLS1 was sequenced and found to contain four genes, from $x e r C$, ygiB, uvrD to $y g i E$. The other suppressor clone, pLS2 encoded rhlE, $y b i A, \operatorname{din} G$ and $y b i B$ (fig. 3a).

To identify the exact gene that suppresses the lethality of the JA30 strain, two derivatives of pLS1 were constructed by PCR using pLS1 as a template, yielding pLS1a and pLS1b. When pLS1b was transformed into JA30S, it retained the ability to suppress the growth-defective phenotype of the JA30 strain, suggesting that the ORF of $y$ giB does not contribute to the suppression observed. Likewise, cell growth was also supported by pLS2a, pLS2b and pLS2d that were constructed from pLS2 by PCR amplifications. However, the suppression activity was lost when cells harbored the plasmid pLS2c, in which the $\operatorname{din} G$ gene was disrupted (fig. 3b). Note that rhlE encoding an ATPdependent DEAD box RNA-helicase did not suppress the
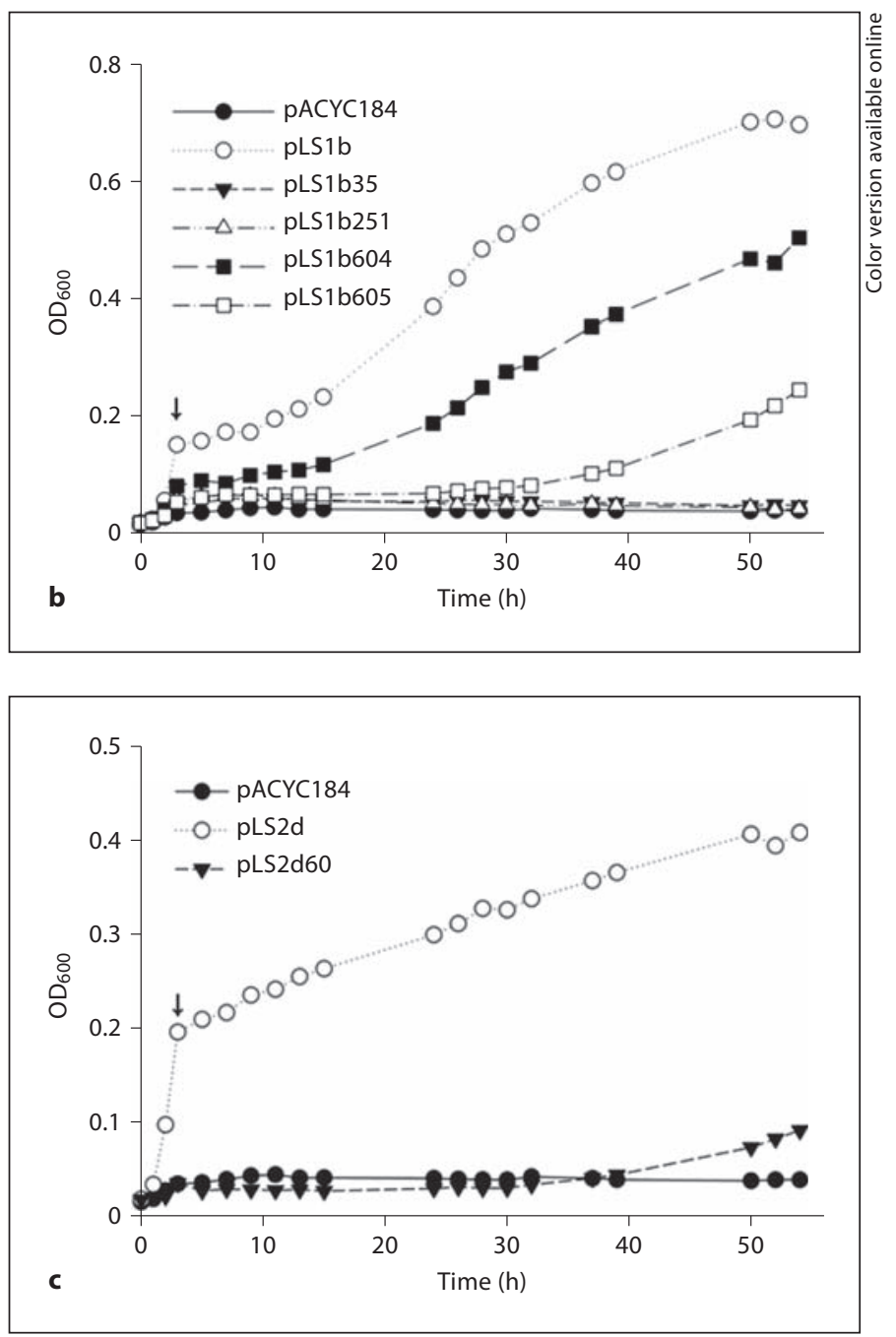

phenotype. Next, we monitored the growth curves of JA30 cells expressing UvrD or DinG in a liquid medium at low temperature. When JA30 cells were transformed with pLS1, pLS1b, pLS2 or pLS2d, the growth rates of these transformants at $15^{\circ} \mathrm{C}$ appeared to be similar to that of cells expressing CspA (fig. 3c, d). These results suggest that the $u v r D$ and $\operatorname{din} G$ genes are responsible for the suppression of growth inhibition of the JA30 strain.

\section{ATPase and DNA-Binding Activities Are Essential for the Suppression}

Both UvrD and DinG are ATP-dependent DNA helicases, and their ATP-binding and DNA-binding domains mutually regulate their activity. $\mathrm{UvrD}(\mathrm{K} 35 \mathrm{I})$, a substitution of lysine to isoleucine in Walker motif I, was shown to disrupt both ATPase and DNA-binding activities [Maluf et al., 2003]. Brosh and Matson [1997] replaced 


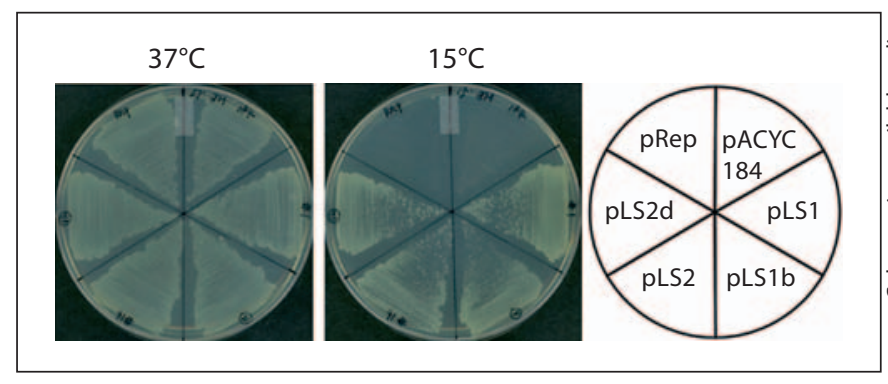

Fig. 5. UvrD and DinG but not Rep as a suppressor. The LACE cells, JA30, were transformed with a control vector, four suppressor clones or pRep encoding a replicative ATP-dependent DNA helicase. Transformants formed at $37^{\circ} \mathrm{C}$ were restreaked on $\mathrm{LB}+$ $\mathrm{Ap}+\mathrm{Cm}$ plates. The plates were incubated at $37^{\circ} \mathrm{C}$ and $15^{\circ} \mathrm{C}$.

Gln ${ }^{251}$, a highly conserved residue, in helicase motif III of UvrD with glutamic acid, and observed that the ATPase activity was severely hampered, while DNA-binding activity was sustained comparable to that of the wild-type UvrD protein. Other two mutants, $\operatorname{UvrD}(\mathrm{T} 604 \mathrm{~A})$ and $\mathrm{UvrD}(\mathrm{R} 605 \mathrm{~A})$ were shown to have serious defect in ssDNA-binding in the absence of ATP and ATP hydrolysis without impacting DNA-binding, respectively [Hall et al., 1998]. To further verify that these two helicases indeed act as suppressors and understand the mechanism of suppression, those mutations were introduced in pLS1b, yielding pLS1b35, pLS1b251, pLS1b604 and pLS1b605. For DinG, Lys ${ }^{60}$, a highly conserved residue in Walker motif I of ATPase domain was substituted with alanine, yielding pLS2d60. These mutant plasmids were transformed into JA30 cells, and transformants were incubated at $37^{\circ} \mathrm{C}$ and $15^{\circ} \mathrm{C}$ to observe the suppression effect. None of transformants were able to suppress the lethality of JA 30 cells at $15^{\circ} \mathrm{C}$, except for the transformants harboring wild-type plasmids, pLS1b and pLS2d (fig. 4a). However, interestingly, in a liquid culture, JA30 cells expressing $\operatorname{UvrD}(\mathrm{T} 604 \mathrm{~A})$ were able to slowly resume the growth approximately after $10 \mathrm{~h}$, while pLS1b605 was not able to suppress the growth defect of JA30 cells until $30 \mathrm{~h}$ of incubation (fig. 4b). This is likely due to the severely defective ATPase activity of $\operatorname{UrD}(\mathrm{R} 605 \mathrm{~A})$, even though both mutants retained almost intact nucleic acid-binding ability [Hall et al., 1998]. Likewise, the mutations K35A and Q251E in the UvrD protein completely abolished the suppression effect. The cells producing DinG(K60A) slowly resumed the growth approximately at $40 \mathrm{~h}$ time point (fig. 4c). These results imply that ATP-binding activity is more essential for UvrD and DinG to bind nucleic acids and that the nucleic acid-binding activities of both UvrD and DinG are critically associated with the suppression of the LACE effect.

\section{UvrD and DinG, but Not Rep as a Suppressor}

In E. coli, fourteen DNA helicases have been identified [Tuteja and Tuteja, 2004b], and among which UvrD and DinG were identified in the present study, as suppressors that belong to repair DNA helicase family [Tuteja and Tuteja, 2004a]. Another replicative DNA helicase Rep is a member of superfamily 1 DNA helicase. Recently, Boubakri et al. [2010] showed that Rep in conjunction with UvrD or DinG cooperatively functions to promote DNA replication across highly transcribed gene by removing RNA polymerase. rep-uvrD double mutant is lethal, and cells lacking two of these three helicases were elongated, suggesting synergistic and overlapping functions among three helicases [Boubakri et al., 2010].

Even though the rep gene was not initially isolated as a suppressor, we tested if Rep is able to suppress the phenotype of JA30 at low temperature. pRep was constructed as described in 'Experimental Procedures'. pRep or four suppressor clones were transformed into JA30, and transformants formed at $37^{\circ} \mathrm{C}$ were streaked on LB plates followed by incubation at $37^{\circ} \mathrm{C}$ or $15^{\circ} \mathrm{C}$. The result showed that JA30 cells harboring pRep did not grow at low temperature $\left(15^{\circ} \mathrm{C}\right)$, while other suppressor clones supported the growth at low temperature. This suggests that the overlapping function of UvrD and DinG is distinct from that of Rep (fig. 5).

\section{Discussion}

In this study, we showed that overexpression of both $5^{\prime}-U T R$ and truncated CspA mutant proteins caused the LACE phenotype, and polysomes appeared to be stalled at stop codons tested. Even without a premature nonsense codon in $\operatorname{csp} A$ mRNA, the production of CspAa, CspAb or CspAc resulted in lethal phenotype. Peculiarly, expression of CspAa in BX02 did not show dramatic polysome stallings (fig. 2), nevertheless, pJJG02a still caused LACE. However, a quadruple deletion BX04 strain was capable of growing at $15^{\circ} \mathrm{C}$ when it expressed CspAa (online suppl. fig. S2), suggesting that CspAa lost its specific function with respect to the $5^{\prime}$-UTR under LACE, while it can still function as an RNA chaperone in the BX04 $(\triangle c s p A B G E)$ strain. The primary cause of LACE seems to be production of either truncated or point mutant protein which hampers its specific association with the $5^{\prime}-U T R$. This interaction may directly interfere with the binding 
of ribosomes to mRNA or dissociate duplex formation between $5^{\prime}-U T R$ and $16 \mathrm{~S}$ rRNA to reduce translation rate. In turn, ribosome-free mRNA likely becomes vulnerable to RNase degradation, leading to repression of $\operatorname{csp} A$ transcripts during acclimation phase.

Even though it is possible that under the LACE condition, translation termination factors were not properly produced, which consequently impairs the termination process [Xia et al., 2001c], it is still tempting to speculate that the impaired translation termination process does not directly cause the LACE effect. This idea was further tested by overexpression of either one of two release factors, RF-1 and RF-2, of translation termination in LACE cells. Those release factors that redundantly recognize TAA did not rescue the growth at low temperature (online suppl. fig. S4). Furthermore, changes of TAA to TAG or TGA did not alleviate the LACE phenotype (online suppl. fig. S5). Interestingly, this LACE effect was not applicable to three cold shock-inducible $\operatorname{csp} B, \operatorname{csp} G$ or $\operatorname{cspI}$ genes that also contain a long $5^{\prime}$-UTR [Wang et al., 1999]. When a premature stop codon at 31st position in each gene was introduced, none of the mutant plasmids showed any growth inhibition when transformed in respective deletion strain (online suppl. fig. S6), suggesting that LACE may be restricted to $\operatorname{csp} A$ mRNA, mainly due to the highly translatable nature of its transcripts.

Not only a quadruple deletion BX04 was functionally complemented by CspA homologues [Xia et al., 2001a], but also the LACE effect was suppressed by overexpressed CspA and to a lesser extent, CspB proteins [Jiang et al., 1996b]. Peculiarly, however, neither any of the CspA homologues nor RNA helicases were isolated as a suppressor from our library screening. This may be due to (a) an inadequate expression level of $\mathrm{CspC}, \mathrm{CspF}, \mathrm{CspH}$ and CspI from library clones and/or (b) a unique role of CspA in its negative auto-regulation related with $5^{\prime}-U T R$.

The unexpected findings of two DNA helicases as suppressors are somewhat intriguing, because of their apparent roles in DNA metabolism. Both UvrD and DinG are DNA damage-inducible DNA helicases. UvrD is a member of superfamily 1 DNA helicase and translocates in the $3^{\prime} \rightarrow 5^{\prime}$ direction on ssDNA to carry out nucleotide excision repair and mismatch repair [Runyon et al., 1990; Tuteja and Tuteja, 2004b]. Unlike UvrD, DinG belongs to superfamily 2 DNA helicase, and is an SOS-regulated protein which translocates in the $5^{\prime} \rightarrow 3^{\prime}$ direction on ssDNA [Courcelle et al., 2001; Lewis et al., 1992; Tuteja and Tuteja, 2004b]. As described above, UvrD or DinG with a help of Rep remove actively transcribing RNA poly- merase where DNA replication head-on collides [Boubakri et al., 2010]. This is one of possible suppression mechanisms, as the transcription of $\operatorname{cspA}$ in pJJG02 occurs in the direction of plasmid replication.

Notably, UvrD as well as DinG were shown to unwind in vitro DNA-DNA duplexes or DNA-RNA hybrids [Matson, 1989; Voloshin and Camerini-Otero, 2007]. Thus, one may speculate that the nascent $\operatorname{csp} A$ transcripts are dissociated from RNA polymerase, leading to reduction in cspA expression. Another possibility is that in Bacillus subtilis, the N-terminal region of DinG share a homology with an exonuclease domain [Moser et al., 1997], raising a possibility that DinG may modulate the metabolism of $\operatorname{csp} A$ mRNAs in our suppression system. UvrD was reported to function as a mutator when overexpressed in $E$. coli, triggering +1 frame shift in the lac $Z$ gene but not a base substitution [Yang et al., 2004], implying that a premature non-sense codon in mutant $\operatorname{csp} A$ mRNA is recognized otherwise by overexpressed UvrD. However, this is unlikely in that the frame shift mutation would not lead to formation of functional, full-length CspA. Lastly, we do not rule out a possibility that UvrD and DinG function as a negative trans-factor in $\operatorname{csp} A$ repression.

Based on the present studies, it seems that CspA plays a unique role in its own transcripts, and our data show that UvrD and DinG are directly involved in the suppression of LACE. Further investigation is underway to unveil how UvrD and DinG suppress the deleterious function of mutant $\operatorname{csp} A$ mRNA. Our findings of UvrD and DinG as suppressors for LACE may offer a system to investigate the novel roles of those DNA helicases; furthermore, the unique function of $5^{\prime}-U T R$ of $\operatorname{cspA}$ mRNA at low temperature shall be comprehended.

\section{Experimental Procedures}

\section{Bacterial Strains and Growth Conditions}

E. coli strains JM83 (F ara (lac-proAB) rpsL $\left(\mathrm{Sm}^{\mathrm{R}}\right)$ [ $\$ 80$ dlac (lacZ) M15] thi) [Tanabe et al., 1992], BX02 (JM83, $\Delta c s p A G)$ [Xia et al., 2001a] and BX04 (JM83, $\Delta c s p A B G E$ ) [Xia et al., 2001a] were routinely grown at either $37^{\circ} \mathrm{C}$ or $15^{\circ} \mathrm{C}$ in $\mathrm{LB}$ medium without IPTG (isopropyl $\beta$ - $D$-thiogalactopyranoside), unless indicated otherwise. To observe colony formation at $15^{\circ} \mathrm{C}$, plates were incubated for 3-4 days at low temperature. Antibiotics were used at the concentrations of 50, 35 and $50 \mu \mathrm{g} / \mathrm{ml}$ for ampicillin (Ap), kanamycin $(\mathrm{Km})$ and chloramphenicol $(\mathrm{Cm})$, respectively. To measure optical density of $E$. coli cultures, samples were taken from cell cultures, and were five-times diluted with LB medium. Turbidity was measured at $600 \mathrm{~nm}$. The growth curves were measured from two independent experiments, and the results were reproducible. 
Table 1. Strains and plasmids used in this study and their genotypes

\begin{tabular}{|c|c|c|}
\hline Strains/plasmids & Genotypes & Reference or source \\
\hline \multicolumn{3}{|l|}{ Strains } \\
\hline JM83 & F ara (lac-proAB) rpsL $\left(\mathrm{Sm}^{\mathrm{R}}\right)$ [ $\phi 80$ dlac (lacZ) M15] thi (a wild-type strain) & Tanabe et al., 1992 \\
\hline BX02 & $\Delta \operatorname{csp} A \Delta \operatorname{csp} G, \mathrm{JM} 83$ & Xia et al., 2001a \\
\hline BX04 & $\Delta \operatorname{csp} A \Delta \operatorname{csp} B \Delta \operatorname{csp} G \Delta \operatorname{csp} E, \mathrm{JM} 83$ & Xia et al., 2001a \\
\hline \multicolumn{3}{|l|}{ Plasmids } \\
\hline pJJG02a & $\operatorname{cspA}(\mathrm{W} 11 \mathrm{~A}), \mathrm{pJJG} 02$ & This study \\
\hline pJJG02b & $\operatorname{csp} A(\mathrm{~F} 18 \mathrm{~A}, \mathrm{~F} 20 \mathrm{~A}), \mathrm{pJJG} 02$ & This study \\
\hline pJJG02c & $\operatorname{csp} A(\mathrm{~F} 31 \mathrm{~A}, \mathrm{H} 33 \mathrm{~A}, \mathrm{~F} 34 \mathrm{~A}), \mathrm{pJJG} 02$ & This study \\
\hline pA30S & TAA at 31 st aa residue, pJJG02 & Xia et al., 2001c \\
\hline pA51S & TAA at 52nd aa residue, pJJG02 & This study \\
\hline pA66S & TAA at 67 th aa residue, pJJG02 & This study \\
\hline pACYC184 & $\mathrm{Cm}^{\mathrm{R}}, \mathrm{Tc}^{\mathrm{R}}$, ori $\mathrm{p} 15 \mathrm{~A}$, cloning vector & New England Biolabs \\
\hline pACYCCspA & $\operatorname{csp} A^{+}, \mathrm{pACYC} 184$ & This study \\
\hline pLS1 & uvrD ${ }^{+}$, pACYC184 (an E. coli genomic library clone) & This study \\
\hline pLS1a & A derivative of $\mathrm{pLS} 1$ & This study \\
\hline pLS1b & A derivative of pLS1 & This study \\
\hline pLS2 & $\operatorname{din} G^{+}$, pACYC184 (an E. coli genomic library clone) & This study \\
\hline pLS2a & A derivative of $\mathrm{pLS} 2$ & This study \\
\hline pLS2b & A derivative of pLS2 & This study \\
\hline pLS2c & A derivative of pLS2 & This study \\
\hline pLS2d & A derivative of pLS2 & This study \\
\hline pLS1b35 & uvrD (K35A), pLS1b & This study \\
\hline
\end{tabular}

Construction of Mutant cspA Plasmids

Plasmids pA51S, pA54S, pA57S, pA60S, pA63S and pA66S encode a premature stop codon (TAA) at different locations of $\operatorname{csp} A$, and were constructed by site-directed mutagenesis PCR using pJJG02 as a template. In a similar way, plasmids pJJG02a, pJJG02b and pJJG02c containing aa substitutions were cloned using pJJG02 as a template. Each clone in this study was confirmed by sequencing analysis. Table 1 summarizes the strains and plasmids used in this study.

\section{Sucrose Density Gradient Sedimentation}

E. coli strains were grown at $37^{\circ} \mathrm{C}$ in $100 \mathrm{ml}$ of $\mathrm{LB}$ medium to $\log$ phase; then, the cultures were shifted to $15^{\circ} \mathrm{C}$ for $1 \mathrm{~h}$. After cold shock, polysomes were trapped by the addition of $\mathrm{Cm}$ to the culture at a final concentration of $0.1 \mathrm{mg} / \mathrm{ml}$. After additional 4-min incubation, cells were harvested in a pre-chilled 50 -ml tube followed by centrifugation for $10 \mathrm{~min}$ at $4^{\circ} \mathrm{C}$. The cell pellets were resuspended in $1 \mathrm{ml}$ of buffer $\mathrm{BP}$ [20 mM Tris- $\mathrm{HCl}$ ( $\mathrm{pH} 7.5), 10$
$\mathrm{mM} \mathrm{MgCl}_{2}, 100 \mathrm{mM} \mathrm{NH}_{4} \mathrm{Cl}$ and $5 \mathrm{mM} \beta$-mercaptoethanol] containing $1 \mathrm{mg} / \mathrm{ml}$ lysozyme. The cells were lysed by two rounds of freeze and thaw, and the lysates were then clarified by centrifugation for $15 \mathrm{~min}$ at $14,000 \mathrm{rpm}$. in a microcentrifuge at $4^{\circ} \mathrm{C}$. Polysomes were resolved as described previously with minor modifications [Hwang and Inouye, 2006; Xia et al., 2001c].

Construction of an E. coli Genomic Library and Screening for Suppressor Genes

Genomic DNA from the BX04 (JM83, $\triangle c s p A B G E)$ [Xia et al., 2001a] was prepared, and $100 \mu \mathrm{g}$ of genomic DNA was partially digested with AciI. Then, the digested genomic DNA fragments of 2-5 kb were ligated into ClaI site of pACYC184 $\left(\mathrm{Cm}^{\mathrm{R}}\right.$ and $\mathrm{Tc}^{\mathrm{R}}$, New England Biolabs). The genomic library of $10 \mu \mathrm{g}$ was transformed into strain JA30 (JM83 cells harboring pA30S), and transformants were plated on LB plates containing Ap and Cm. Note that the pACYC184-carrying genomic library is compatible with 
pA30S as they contain different replication origins, p15A and $\mathrm{ColE1}$, respectively. The plates were incubated at $15^{\circ} \mathrm{C}$ for 4 days. In total, 52 colonies were formed at low temperature, and plasmids were extracted from those colonies. The extracted plasmids were transformed into $\mathrm{DH} 5 \alpha$ cells, and transformants were plated on $\mathrm{LB}$ plates containing $\mathrm{Cm}$ to remove $\mathrm{pA} 30 \mathrm{~S}\left(\mathrm{Ap}^{\mathrm{R}}\right)$. Subsequently, a homogeneous library clone was purified from each Cm-resistant colony. The purified library clones were retransformed into JA30 cells to confirm their abilities to suppress the growth inhibition of strain JA30 at $15^{\circ} \mathrm{C}$. Eleven clones that consistently suppress LACE were sequenced from both ends to identify the inserted fragments.

Cloning and Site-Directed Mutagenesis of uvrD and dinG Truncated plasmids pLS1a, pLS1b, pLS2a, pLS2b, pLS2c and pLS2d were constructed by PCR using either pLS1 or pLS2 as a template. The PCR product was digested with HindIII-XbaI, and the digested DNA fragment was ligated into the HindIII-XbaI site of pACYC184. To introduce a single amino acid mutation in the uvrD or $\operatorname{din} G$ genes, site-directed mutagenesis was carried out using pLS1b and pLS2d as templates, yielding pLS1b35, pLS1b251, pLS1b604, pLS1b605 and pLS2d60. Each mutation was confirmed by sequencing analysis. The rep gene containing its own promoter was amplified by PCR, the HindIII-XbaI-digested DNA fragment of rep was ligated into the HindIII-XbaI site of pACYC184, yielding pRep.

\section{Acknowledgements}

We would like to thank Ms. Adriana Martina and Vedanta Malhoe for their assistance. NIH RO3 grant 76900 to S.P. is acknowledged.

\section{References}

Bae W, Jones PG, Inouye M: CspA, the major cold shock protein of Escherichia coli, negatively regulates its own gene expression. J Bacteriol 1997;179:7081-7088.

Boubakri H, de Septenville AL, Viguera E, Michel B: The helicases DinG, Rep and UvrD cooperate to promote replication across transcription units in vivo. EMBO J 2010;29: $145-157$.

Brandi A, Pon CL: Expression of Escherichia coli cspA during early exponential growth at 37 degrees C. Gene 2012;492:382-388.

-Brosh RM, Matson SW: A point mutation in Escherichia coli DNA helicase II renders the enzyme nonfunctional in two DNA repair pathways - evidence for initiation of unwinding from a nick in vivo. J Biol Chem 1997;272:572-579.

Courcelle J, Khodursky A, Peter B, Brown PO, Hanawalt PC: Comparative gene expression profiles following UV exposure in wild-type and SOS-deficient Escherichia coli. Genetics 2001;158:41-64.

Fang L, Jiang WN, Bae WH, Inouye M: Promoter-independent cold-shock induction of cspA and its derepression at 37 degrees $\mathrm{C}$ by mRNA stabilization. Mol Microbiol 1997;23 355-364.

Fang L, Xia B, Inouye M: Transcription of cspA, the gene for the major cold-shock protein of Escherichia coli, is negatively regulated at 37 degrees $\mathrm{C}$ by the $5^{\prime}$-untranslated region of its mRNA. FEMS Microbiol Lett 1999;176:3943.

- Feng WQ, Tejero R, Zimmerman DE, Inouye M, Montelione GT: Solution NMR structure and backbone dynamics of the major coldshock protein (CspA) from Escherichia coli: evidence for conformational dynamics in the single-stranded RNA-binding site. Biochemistry 1998;37:10881-10896.
Giuliodori AM, Branki A, Gualerzi CO, Pon CL: Preferential translation of cold-shock mRNAs during cold adaptation. RNA 2004; 10:265-276.

Giuliodori AM, Di Pietro F, Marzi S, Masquida B, Wagner R, Romby P, Gualerzi CO, Pon CL: The cspA mRNA is a thermosensor that modulates translation of the cold-shock protein CspA. Mol Cell 2010;37:21-33.

Goldenberg D, Azar I, Oppenheim AB: Differential mRNA stability of the cspA gene in the cold-shock response of Escherichia coli. Mol Microbiol 1996;19:241-248.

Goldstein J, Pollitt NS, Inouye M: Major cold shock protein of Escherichia coli. Proc Natl Acad Sci USA 1990;87:283-287.

-Gualerzi CO, Giuliodori AM, Pon CL: Transcriptional and post-transcriptional control of cold-shock genes. J Mol Biol 2003;331:527539.

Hall MC, Ozsoy AZ, Matson SW: Site-directed mutations in motif VI of Escherichia coli DNA helicase II result in multiple biochemical defects: evidence for the involvement of motif VI in the coupling of ATPase and DNA binding activities via conformational changes. J Mol Biol 1998;277:257-271.

-Hillier BJ, Rodriguez HM, Gregoret LM: Coupling protein stability and protein function in Escherichia coli CspA. Fold Des 1998;3: 87-93.

Hwang J, Inouye M: The tandem GTPase, Der, is essential for the biogenesis of 50S ribosomal subunits in Escherichia coli. Mol Microbiol 2006;61:1660-1672.

Jiang WN, Fang L, Inouye M: The role of the 5'end untranslated region of the mRNA for CspA, the major cold-shock protein of Escherichia coli, in cold-shock adaptation. J Bacteriol 1996a;178:4919-4925.
Jiang WN, Hou Y, Inouye M: CspA, the major cold-shock protein of Escherichia coli, is an RNA chaperone. J Biol Chem 1997;272:196202

Jiang WN, Li F, Inouye M: Complete growth inhibition of Escherichia coli by ribosome trapping with truncated cspA mRNA at low temperature. Genes Cells 1996b;1:965-976.

Lewis LK, Jenkins ME, Mount DW: Isolation of DNA damage-inducible promoters in Escherichia coli: regulation of polB (din A), dinG, and $\operatorname{din} \mathrm{H}$ by LexA repressor. J Bacteriol 1992;174:3377-3385.

-Maluf NK, Fischer CJ, Lohman TM: A dimer of Escherichia coli UvrD is the active form of the helicase in vitro. J Mol Biol 2003;325: 913-935.

Matson SW: Escherichia coli DNA helicase II (uvrD gene product) catalyzes the unwinding of DNA.RNA hybrids in vitro. Proc Natl Acad Sci USA 1989;86:4430-4434.

Mitta M, Fang L, Inouye M: Deletion analysis of cspA of Escherichia coli: requirement of the AT-rich UP element for cspA transcription and the downstream box in the coding region for its cold shock induction. Mol Microbiol 1997;26:321-335.

- Moser MJ, Holley WR, Chatterjee A, Mian IS: The proofreading domain of Escherichia coli DNA polymerase I and other DNA and/or RNA exonuclease domains. Nucleic Acids Res 1997;25:5110-5118.

Phadtare S: Recent developments in bacterial cold-shock response. Curr Issues Mol Biol 2004;6:125-136.

Phadtare S, Inouye M: Genome-wide transcriptional analysis of the cold shock response in wild-type and cold-sensitive, quadruplecsp-deletion strains of Escherichia coli. J Bacteriol 2004;186:7007-7014. 
Phadtare S, Inouye M, Severinov K: The nucleic acid melting activity of Escherichia coli CspE is critical for transcription antitermination and cold acclimation of cells. J Biol Chem 2002b;277:7239-7245.

Phadtare S, Inouye M, Severinov K: The mechanism of nucleic acid melting by a CspA family protein. J Mol Biol 2004;337:147-155.

- Phadtare S, Severinov K: Extended -10 motif is critical for activity of the cspA promoter but does not contribute to low-temperature transcription. J Bacteriol 2005; 187:6584-6589.

- Phadtare S, Tyagi S, Inouye M, Severinov K Three amino acids in Escherichia coli CspE surface-exposed aromatic patch are critical for nucleic acid melting activity leading to transcription antitermination and cold acclimation of cells. J Biol Chem 2002a;277: 46706-46711.

- Runyon GT, Bear DG, Lohman TM: Escherichia coli helicase II (UvrD) protein initiates DNA unwinding at nicks and blunt ends. Proc Natl Acad Sci USA 1990;87:6383-6387.
Schindelin $\mathrm{H}$, Jiang WN, Inouye M, Heinemann $\mathrm{U}$ : Crystal-structure of CspA, the major cold shock protein of Escherichia coli. Proc Natl Acad Sci USA 1994;91:5119-5123.

- Tanabe H, Goldstein J, Yang MZ, Inouye M: Identification of the promoter region of the Escherichia coli major cold shock gene, CspA. J Bacteriol 1992;174:3867-3873.

Tuteja N, Tuteja R: Unraveling DNA helicases. Motif, structure, mechanism and function (vol 271, p 1849, 2004). Eur J Biochem 2004a;271:3283-3283.

Tuteja N, Tuteja R: Prokaryotic and eukaryotic DNA helicases - essential molecular motor proteins for cellular machinery. Eur J Biochem 2004b;271:1835-1848.

-Voloshin ON, Camerini-Otero RD: The DinG protein from Escherichia coli is a structurespecific helicase. J Biol Chem 2007;282: 18437-18447.

Wang N, Yamanaka K, Inouye M: CspI, the ninth member of the CspA family of Escherichia coli, is induced upon cold shock. J Bacteriol 1999;181:1603-1609.

-Xia B, Etchegaray JP, Inouye M: Nonsense mutations in cspA cause ribosome trapping leading to complete growth inhibition and cell death at low temperature in Escherichia coli. J Biol Chem 2001c;276:35581-35588.
Xia B, Ke HP, Inouye M: Acquirement of cold sensitivity by quadruple deletion of the cspA family and its suppression by PNPase S1 domain in Escherichia coli. Mol Microbiol 2001a;40:179-188.

Xia B, Ke H, Inouye M: Acquirement of cold sensitivity by quadruple deletion of the cspA family and its suppression by PNPase S1 domain in Escherichia coli. Mol Microbiol 2001b;40:179-188.

Xia B, Ke H, Jiang W, Inouye M: The Cold Box stem-loop proximal to the $5^{\prime}$-end of the Escherichia coli cspA gene stabilizes its mRNA at low temperature. J Biol Chem 2002;277: 6005-6011.

- Yamanaka K, Mitta M, Inouye M: Mutation analysis of the $5^{\prime}$-untranslated region of the cold shock cspA mRNA of Escherichia coli. J Bacteriol 1999;181:6284-6291.

-Yang H, Wolff E, Kim M, Diep A, Miller JH: Identification of mutator genes and mutational pathways in Escherichia coli using a multicopy cloning approach. Mol Microbiol 2004;53:283-295. 